\title{
Determination of the Ankle-brachial Index in Type 2 Diabetic Patients with an Automatic Oscillometric Device
}

\author{
Aurelio Sessa*, Italo Paolini, Carlo Fedele Marulli, Antonino Di Guardo, Gerardo Medea \\ Italian College of General Practitioners and Primary Care, Florence, Italy \\ Email address: \\ sessa.aurelio@simg.it (A. Sessa) \\ ${ }^{*}$ Corresponding author

\section{To cite this article:} \\ Aurelio Sessa, Italo Paolini, Carlo Fedele Marulli, Antonino Di Guardo, Gerardo Medea. Determination of the Ankle-brachial Index in Type \\ 2 Diabetic Patients with an Automatic Oscillometric Device. European Journal of Clinical and Biomedical Sciences. \\ Vol. 5, No. 1, 2019, pp. 5-8. doi: 10.11648/j.ejcbs.20190501.12
}

Received: February 19, 2019; Accepted: March 30, 2019; Published: April 18, 2019

\begin{abstract}
An altered ankle-brachial index (ABI) is an indicator of peripheral arterial disease (PAD). Usually the measurement of the systolic pressure in both brachial arteries and pedal pulses is performed with a continuous-wave Doppler ultrasound. Recently an oscillometric automated device is available to measure ABI. This instrument is a simple to use, fast and accurate method suitable for common use in clinical practice. 701 patients with type 2 diabetes who attended consecutively in office were studied by 24 General Practitioners (GPs). 74 patients had an abnormal ABI $(\leq 0.90), 240$ a borderline ABI $(0-$ 90-0.99) and 7 patients $\mathrm{ABI} \geq 1.40$. All these patients received a Doppler ultrasound examination and 117 had an asymptomatic PAD. GPs reported that the device was easy to use and that it can be an useful instrument of early diagnosis of PAD in daily practice.
\end{abstract}

Keywords: Peripheral Arterial Disease, Ankle-brachial Index, Automatic Oscillometric Device, Type 2 Diabetes

\section{Introduction}

Peripheral arterial disease (PAD) is an atherosclerotic process leading to the reduction of the diameter of the major distal arteries in the aortic arch. A progression of stenosis results in a reduction of arterial flow and claudication, which is the most common and visible clinical symptom. Only $10 \%$ of patients with PAD show typical claudication; $50 \%$ of patients may suffer from an atypical pain in the legs and $40 \%$ of patients are asymptomatic [1]. The most important risk factors for PAD include diabetes, smoking, hypertension, age, hypercholesterolemia and chronic renal failure [2]. Smoking and diabetes are associated with a higher relative risk of PAD in the lower limbs. The Italian 2018 Standards for the Treatment of Diabetes Mellitus recommend the measurement of the ankle-brachial pressure index (Ankle Brachial Index, $\mathrm{ABI}$ ) for all patients over the age of 40 with type 2 diabetes and those diagnosed with diabetes over 20 years ago [3]. Furthermore, the American Diabetes Association recommends the measurement of ABI in all diabetic patients who are over 50 years old and/or who have been diagnosed with diabetes more than 10 years ago or who were smokers [4].

Ankle-brachial pressure index. The ABI is the ratio between arterial blood pressure at the ankle and the arm.

It is an efficient and low cost method for establishing a diagnosis of PAD. The classical measurement methodology involves the use of two blood pressure cuffs, one on the ankle and the other on the arm. Once the cuff is inflated with air and slowly deflated, a pulse wave is recorded at the ankle using a Doppler probe and systolic pressure is measured at the foot's dorsal or posterior tibial artery. The same process is repeated for the arm by detecting the pulse wave and measuring the systolic blood pressure of the brachial artery. It possesses a high specificity (98\%) and sensitivity (90\%) [5]. The ratio between the two values is the ankle-brachial index. The interpretation of the results is shown in Table 1 [6].

Table 1. Interpretation of ABI values.

\begin{tabular}{ll}
\hline Ankle-brachial index (ABI) & Interpretation \\
\hline$\leq 0.90$ & Peripheral arterial disease \\
$0.91-0.99$ & Borderline \\
$1.00-1.39$ & Normal \\
$\geq 1.40$ & Artery non compressible \\
\hline
\end{tabular}


The greatest limitations of the ABI measurement in daily practice is the time it takes to measure, having the suitable equipment and the ability to use it $[7,8]$. An easy to use device that can be automated and which does not require particular specialist skills can simplify ABI detection, anticipate and increase the diagnosis of PAD in groups of the population that are at risk. The automatic oscillometric measurement of blood pressure is now widely used, accurate and easy to use [6]. This process, compared with the classic method, which involves the use of Doppler sonography, is practically superimposable and a strong correlation between the two methods has been demonstrated in various studies [6, 9-11].

\section{Aim of the Study}

The aim of the study is to evaluate the use of an automatic oscillometric device for the measurement of the ABI as part of good clinical practice that provides this assessment in diabetic patients.

\section{Methods}

Twenty-four GPs trained using this device, participated in this study and were invited to measure the ABI of the first 30 diabetic patients who would present themselves at the clinic for any reason. Each GP was provided with an iHealth $\mathrm{CardioLab}^{\circledR}$ - ABI Wireless device (Figure 1) which is composed of two auto-inflating cuffs that are synchronized and connected wirelessly to an Apple iPad with an ad hoc application. The purpose of this investigation was explained to the patient and, having consented, the patient was invited to lie on the examination bed. First, the pulse waves of the femoral, posterior tibial and dorsal arteries were recorded. Once both limbs were measured, the lowest ABI value was recorded. The medical record was then checked to see if an arterial Doppler ultrasound of the lower limbs was already required and, if necessary, could be claimed as normal good clinical practice after the medical examination.

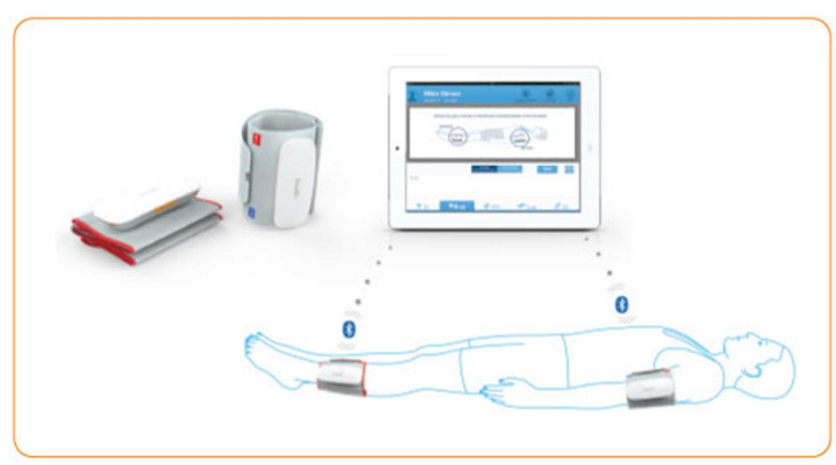

Figure 1. iHealth Cardiolab ${ }^{\circledR}-$ ABI Wireless device.

\section{Results}

706 patients with type 2 diabetes were examined (386 males and 320 females), 5 of which did not have clinical or complete instrumental data and therefore were excluded from the analysis. 28 of 706 patients had already been diagnosed with PAD in their medical records, confirmed by an arterial Doppler ultrasound. Almost half of the patients had a normal ABI value, while more than one third of the patients had a borderline value. An abnormal ABI value $(\leq 0.90)$ was observed in 106 patients $(15.2 \%)$ and a value $\geq 1.40$ in other 7 patients (1\%) (Figure 2 and Table 2).

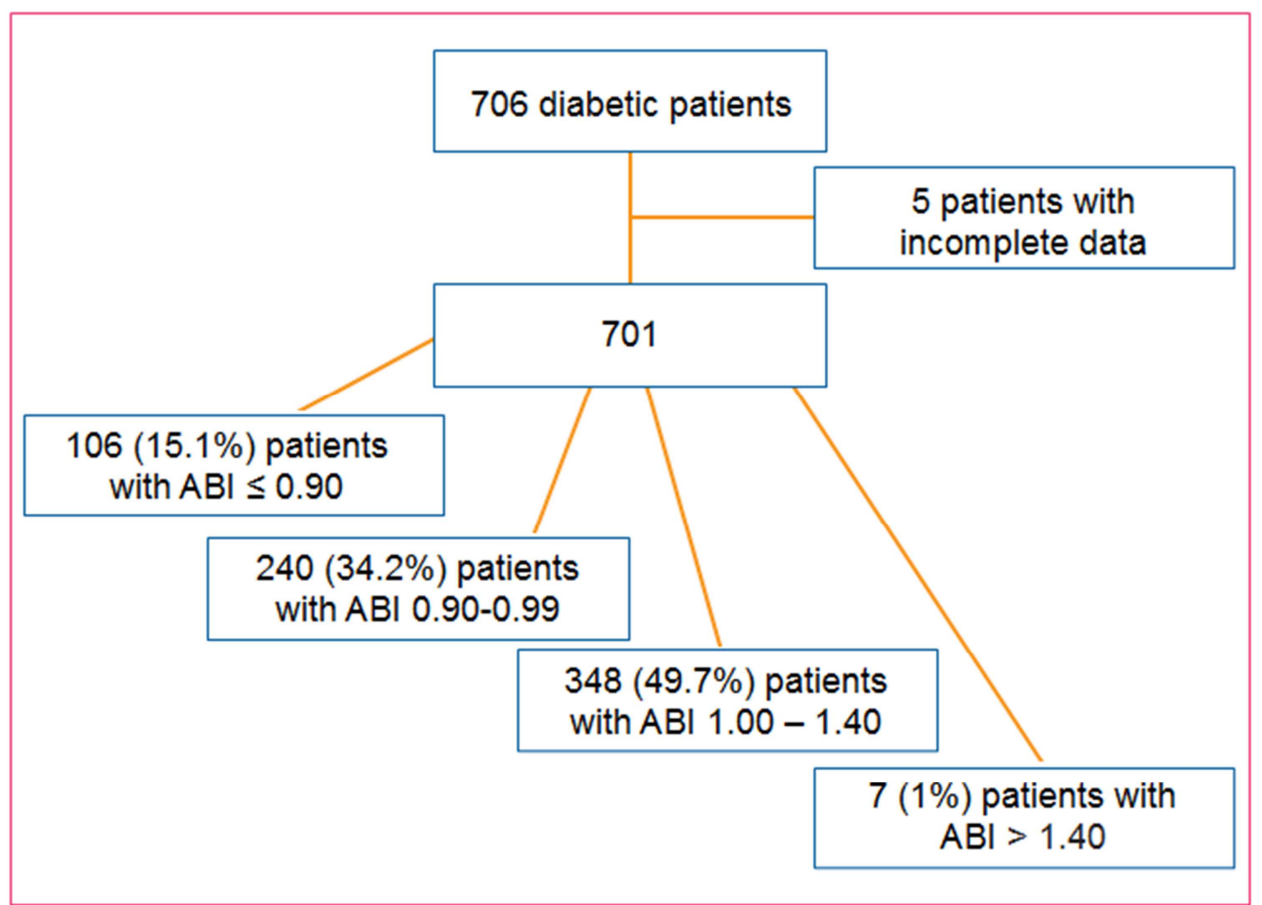

Figure 2. Consecutively examined type 2 diabetic patients (706) with respective ABI values. 
Table 2. Breakdown of patients by ABI values, changes in arterial pulses and pathological arterial doppler ultrasound.

\begin{tabular}{|c|c|c|c|c|c|}
\hline & $\mathrm{ABI} \leq 0.90$ & & ABI $0.90-0.99$ & ABI 1.00-1.39 & $\mathrm{ABI} \geq \mathbf{1 . 4 0}$ \\
\hline Patients n & $\begin{array}{l}106 \\
28 \text { already known with PAD }\end{array}$ & 74 & 240 & 348 & 7 \\
\hline Change in arterial pulse $n .(\%)$ & & $52(70.2 \%)$ & $84(35 \%)$ & 0 & 0 \\
\hline $\begin{array}{l}\text { Patients with pathological arterial } \\
\text { Doppler ultrasound n. (\%) }\end{array}$ & Repeated for 17 as it was dated over a year ago & $56(75.6 \%)$ & $55(22.9 \%)$ & Not performed & $6(85.7 \%)$ \\
\hline
\end{tabular}

The arterial pulses recorded by doctors were altered in about $70 \%$ of cases where patients had an $\mathrm{ABI} \leq 0.90$ and in $35 \%$ of cases where patients had borderline ABI values $(0.90$ to 0.99 ) while pulse alterations were not reported in the remaining group of patients.

Three quarters of patients $(75.5 \%)$ with an $\mathrm{ABI} \leq 0.90$, that did not know to have PAD, had an arterial Doppler ultrasound in the lower limbs that proved pathological while the percentage of those who had a borderline value of $\mathrm{ABI}$ was approximately $22.9 \%$ and $85.7 \%$ for those with an ABI of $\geq 1.40$.

The data gathered in this study also demonstrates that the duration of diabetes is directly proportional to the increase in risk of PAD as shown in Table 3. The decrease in patients who were first diagnosed with diabetes over 21 years ago is probably due to the high mortality that this cohort has suffered due to major cardiovascular events.

Table 3. Patients with $A B I \leq 0.90$ in relation to the number of years since first diagnosis of diabetes (in five year periods).

\begin{tabular}{llll}
\hline $\begin{array}{l}\text { DIABETES } \\
\text { DURATION (years) }\end{array}$ & $\begin{array}{l}\text { Number of } \\
\text { patients }\end{array}$ & $\begin{array}{l}\text { ABI } \\
\text { (average) }\end{array}$ & IC (95\%) \\
\hline $0-5$ & 3 & 0.87 & $0.84-0.89$ \\
$6-10$ & 12 & 0.84 & $0.80-0.87$ \\
$11-15$ & 25 & 0.79 & $0.73-0.85$ \\
$16-20$ & 22 & 0.74 & $0.67-0.80$ \\
$21-25$ & 24 & 0.76 & $0.69-0.83$ \\
$26-30$ & 16 & 0.78 & $0.72-0.84$ \\
$\geq 31$ & 4 & 0.83 & $0.77-0.88$ \\
\hline
\end{tabular}

\section{Discussion}

The data collected is a snapshot of normal clinical practice in which the measurement of the ABI with this oscillometric device was performed on more than 700 patients, who attended consecutively at GPs' practices that participated in the study. There was no significant selections or enlistment bias as patients involved were those who had gone to their family doctor's office for repeat prescriptions, for prescription monitoring or for the assessment of investigations of any kind that had been performed or for other reasons not related to diabetes, also. The systematic use of ABI (once a year) can help to determine a significant proportion of patients with asymptomatic PAD in the presymptomatic phase $(75 \%$ of patients with pathological ABI [ $\leq 0.90]$ and nearly $23 \%$ of diabetic patients with borderline ABI [0.90-0.99] then had an abnormal arterial Doppler ultrasound). The use of this device is completely compatible with daily activities, it requires the same amount of time as for the measurement of blood pressure and it allows the detection of PAD in a percentage of diabetic patients who otherwise would remain undiagnosed. The systematic use of this instrument would even avoid an over-demand for arterial Doppler ultrasound exams, reducing the cost for the National Health Service, waiting lists and inconvenience to patients.

The prevalence of PAD increases also with rising duration of diabetes [12] and the detection of pre-symptomatic PAD allows the physician to implement stricter control of the patient and use a more intensive therapy to improve the metabolic control, as PAD is a progressive disease and the risk of amputation after 5 years is estimated at $1-4 \%$ [13]. A pathological $\mathrm{ABI}$ value is an independent factor of future cardiovascular events [14]. An ABI value of $<0.90$ increases the relative risk of cardiovascular events and all-cause mortality by two to four times [15].

A systematic review examined all studies that had given ABI data at baseline and traced acute coronary disease, strokes and all-cause mortality in patients who had not any cardio- or cerebrovascular events [5]. A low ABI value has a predictive value of $92.7 \%$ for coronary artery disease [15]. After 5 years, $20 \%$ of patients with a PAD have a non-fatal heart attack while $15-30 \%$ die (three-quarters of these from cardiovascular deaths) [16].

\section{Conclusions}

The systematic use of the oscillometric device (iHealth $\mathrm{CardioLab}^{\circledR}$ ) for determining ABI has enabled early diagnosis of PAD in more than $17 \%$ of cases (117 patients out of 673 ). In $20 \%$ of these patients, the pulse recording was normal. If the data prevalence of PAD in this cohort of patients was 4\% (20/701) after using this device, it increased to over $17 \%$, confirming that in type 2 diabetes the prevalence data appears to be significantly underestimated. Its use for patients with known PAD allows the replacement of an outdated arterial Doppler ultrasound that has not been recently rechecked. It can be considered an extraordinary preventive instrument against cardiovascular complications. Associating the oscillometric ABI values with the number of peripheral arterial pulses may also help reduce the number of false negatives and increase the diagnostic sensitivity of the test. For all these reasons, the ABI measurement with this easy to use, reliable and reproducible device can become a method of PAD screening in the daily routine of GPs.

\section{Conflict of Interest}

The authors declare no other conflicts of interest in this work.

There was no funding for this study. The Italian College of General Practitioners and Primary Care bought the device for 
all the participants of the study. The devices are part of the educational tools that the researcher use for the vocational training programme.

Physicians participating in the study: Doriano Battigelli, Luciano Caraceni, Giulio Corgatelli, Gaetano D'Ambrosio, Antonino Di Guardo, Laura Federici, Alessandro Filippi, Gabriella Gentile, Giovanni Giardina, Saffi Ettore Giustini, Piero Grilli, Marco Martinetti, Carlo Fedele Marulli, Antonio Metrucci, Giorgio Carlo Monti, Giulio Nati, Italo Paolini, Gabriella Salladini, Lanfranco Sanna, Gabriele Scattolari, Aurelio Sessa, Paola Tagliabue, Raffaele Tota, Vincenzo Verrone.

\section{References}

[1] Hirsch AT, Criqui MT, Treat-Jacobson D, Regensteiner JG, Creager MA, Olin JW, Krook SH, Hunninghake DB, Comerota AJ, Walsh ME, McDermott MM, Hiatt WR. Peripheral arterial disease detection, awareness and treatment in primary care. JAMA 2001; 286:1317-24.

[2] Fowkes FG, Rudan D, Rudan I, Aboyans V, Denenberg JO, McDermott MM, Norman PE, Sampson UK, Williams LJ, Mensah GA, Criqui MH. Comparison of global extimates of prevalence and risk factors for peripheral artery disease in 2000 and 2010: a systematic review and analysis. Lancet 2013; 382: 1329-40.

[3] www.siditalia.it Standard Italiani per la cura del diabete mellito 2018.

[4] American Diabetes Association. Standard of medical care in diabetes 2018. Diabetes Care 2018; 41(S1):114-31.

[5] Doobay AV, Anand SS. Sensitivity and specificity of the ankle-brachial index to predict future cardiovascular outcomes: a systematic review. Artheriosler Thromb Vasc Biol $2005 ; 25: 1463-9$.

[6] Rosenbaum D, Rodriguez-Carranza S, Laroche P, Bruckert E, Giral P, Gired X. Accuracy of ankle-brachial index using the SVCL, an arm and ankle automated device with synchronized cuffs, in a population with increased cardiovascular risk. Vasc Health Risk Manag 2012; 9: 239-246.

[7] Bendermarcher BLW, Teijink JAW, Willigendael EM, Bartelink ML, Peters RJG, Langenberg M, Buller HR, Prins MH. Applicability of the ankle-brachial index measurement as screening device for high cardiovascular risk: an observational study. BMC Cardiovasc Disord 2012; 12: 59.
[8] Davies JH, Kenkre J, Williams EM. Current utility of the ankle-brachial index (ABI) in general practice: implications for its use in cardiovascular disease screening. BMC Fam Pract 2014; 15: 69-79.

[9] Beckman JA, Higgins CO, Gerhard- Herman M. Automated oscillometric determination of the ankle-brachial index provides accuracy necessary for office practice. Hypertension 2006; 47:35-8.

[10] Ramanathan A, Conaghan PJ, Jenkinson AD, Bishop CR. Comparison of ankle-brachial pressure index measurements using an automated oscillometric device with the standard Doppler ultrasound technique. ANZ J Surg 2003; 73:105-8.

[11] Raines JK, Farrar J, Noicely K, Pena J, Davis WW, Willens HJ, Wallace DD. Ankle/ brachial index in the primary care setting. Vasc Endovascular Surg 2004; 38:131-6.

[12] Nativel M, Potier L, Alexandre L, Baillet-Blando L, Ducasse E, Velho G, Marre M, Roussel R, Rigalleau V, Mohammedi K. Lower extremity arterial disease in patients with diabetes: a contemporary narrative review, Cardiovasc Diabetol 2018; 17: 138-151.

[13] Mohammedi K, Woodward M, Hirakawa Y, Zoungas S, Williams B, Lisheng L, Rodgers A, Mancia G, Neal B, Harrap S, Marre M, Chalmers J, ADVANCE Collaborative Group. Microvascular and macrovascular disease and risk for major peripheral arterial disease in patients with type 2 diabetes. Diabetes Care 2016; 39: 1796-803.

[14] Mohammedi K Woodward M, Zoungas S, Li Q, Harrap S, Patel A, Marre M, Chalmers J. Absence of peripheral pulses and risk of major vascular outcomes in patients with type 2 diabetes. Diabetes Care 2016; 39: 2270-7.

[15] Curry SJ, Krist AH, Owens DK, Barry MJ, Caughey AB, Davidson KW, Doubeni CA, Epling JW Jr, Kemper AR, Kubik M, Landfefeld CS, Mangione CM, Silverstein M, Simon MA, Tseng CW, Wong JB. Screening for peripheral artery disease and cardiovascular disease risk assessment with the ankle-brachial index: US Preventive Services Task Force Recommendation statement. JAMA 2018; 320:177-83.

[16] Pasternak RC, Criqui MH, Benjamin EJ, Fowkes FG, Isselbacher EM, McCullough PA, Wolf PA, Zheng ZJ; American Heart Association.. Writing Group I: epidemiology. Circulation 2004; 109:2605-12. 